\title{
Effect of house dust mite avoidance measures on adult atopic asthma
}

\author{
A J DORWARD, M J COLLOFF, N S MacKAY, C McSHARRY, N C THOMSON \\ From the Departments of Respiratory Medicine and of Immunology, Western Infirmary, Glasgow, and the \\ Department of Zoology, University of Glasgow
}

\begin{abstract}
Twenty one adult patients with asthma, with positive skin test responses to the European house dust mite, Dermatophagoides pteronyssinus, were randomly allocated to a control group or to a group applying house dust mite avoidance measures. These included an initial application of liquid nitrogen to mattresses and bedroom carpets to kill the live house dust mite population. Histamine airway responsiveness, symptom scores, peak expiratory flow rates (PEF), and house dust mite numbers were determined during the two week pretrial and eight week trial periods. Nine patients in each group completed the study. By the end of the study there was a significant reduction in live mites in the "avoidance" group but not in the control group. The avoidance group showed a significant improvement in symptom scores measured on a linear analogue scale, in the number of hours each day spent wheezing (mean reduced from 8.6 to 4.5 hours), and in PEF (1/min) both in the morning (from 364 to 388) and in the evening (from 368 to 392). These changes were not found in the control group. The provocative concentration (PC) of histamine causing a $20 \%$ fall in $\mathrm{FEV}_{1}\left(\mathrm{PC}_{20} \mathrm{FEV}_{1}\right)$ had increased significantly in the avoidance group at eight weeks (from 0.58 to $2.3 \mathrm{mg} / \mathrm{ml}$ ), whereas no change was seen in the control group (from 0.93 to $1.21 \mathrm{mg} / \mathrm{ml}$ ). These results show that house dust mite avoidance, combined with initial killing of the mite by liquid nitrogen, diminishes airway responsiveness and improves asthma symptom control over an eight week period in adult asthmatic patients with house dust mite allergy.
\end{abstract}

The role of house dust mite allergens in the provocation of atopic asthma has become established since 1967, when Voorhorst et al identified Dermtophagoides pteronyssinus as the major source of allergens in house dust.' The first trial of house dust mite avoidance in children resulted in a reduction of house dust mite numbers in the homes of the subjects and an improvement in asthmatic symptoms. ${ }^{2}$ Although these results were encouraging the study was uncontrolled. A randomised trial in children in Vancouver showed an overall improvement in symptoms and a modest improvement in histamine reactivity of the airways. ${ }^{3} \mathrm{~A}$ recent report suggested that the reduction in bronchial reactivity seen in a group of adults with severe asthma in hospital was due to prolonged reduction in house dust mite allergen exposure. ${ }^{4}$ Controlled studies in adults, however, have shown little or no improvements in symptoms ${ }^{56}$ until recently, when Walshaw and Evans were able to show an improvement in bronchial

Address for reprint requests: Dr A J Dorward, Royal Alexandra Infirmary, Paisley PA2 6LX.

Accepted 16 October 1987 reactivity after eight months of vigorous house dust mite avoidance. ${ }^{?}$

In a randomised controlled trial we have examined the effect of eight weeks of house dust mite avoidance measures on non-specific airway responsiveness in adult patients sensitive to the house dust mite. The measures included the application of liquid nitrogen to the bed and bedroom carpets to inhibit the live house dust mite population.

\section{Methods}

Twenty one patients attending the hospital respiratory clinic with symptomatic stable asthma were entered into the study from January to April 1984. All patients had a weal diameter of at least $3 \mathrm{~mm}$ more than the control in response to skin prick testing with $D$ pteronyssinus extract (Bencard). Weal area was measured by planimetry. Only patients with a forced expiratory volume in one second $\left(\mathrm{FEV}_{1}\right)$ of more than $60 \%$ of their predicted value were included. A salbutamol inhaler was used for symptomatic relief and 
beclomethasone diproprionate inhalations were continued if the patient had been stable with this medication for at least four months. Patients who required oral steroids, theophylline, or sodium cromoglycate or who had a cat or dog at home were excluded.

Patients were given a diary card and asked to record the best of two peak expiratory flow (PEF) recordings morning and evening, using a Mini-Wright peak flow meter. They made daily recordings of wheezing (hours a day), the number of puffs of salbutamol used, and a subjective impression of the severity of their asthma by putting a cross on a $10 \mathrm{~cm}$ linear analogue scale. During the two to three week run in period a histamine bronchial provocation test was performed by the method described by Hargreaves et al. ${ }^{8}$ After recording baseline $\mathrm{FEV}_{\text {, }}$ using a dry wedge spirometer (Vitalograph), the subject inhaled for two minutes, wearing a noseclip, with tidal breathing from a Wright's nebuliser driven by air at $50 \mathrm{lb} / \mathrm{in}^{2}(345 \mathrm{kPa})$ at a flow rate of $8 \mathrm{l} / \mathrm{min}$ (the nebuliser output under these conditions is $0 \cdot 15 \mathrm{ml} / \mathrm{min}$ ). $\mathrm{FEV}_{\text {, }}$ was recorded at 90 seconds and at three minutes. Inhalations of phosphate buffered saline was followed at five minute intervals with inhalation of increasing concentrations of phosphate buffered histamine, starting at $0.03 \mathrm{mg} /$ $\mathrm{ml}$, and continuing until the provocative concentration that produced a $20 \%$ fall from control $\mathrm{FEV}_{1}$ $\left(\mathrm{PC}_{20} \mathrm{FEV}_{1}\right)$ was determined. The test was repeated on a separate day. The geometric mean of the two $\mathrm{PC}_{20} \mathrm{FEV}_{1}$ values obtained was taken as the baseline $\mathrm{PC}_{20} \mathrm{FEV}_{1}$. Subsequent challenges were carried out by a different person, who was unaware of the previous baseline values or the group to which the patient had been allocated. After the run in period patients were randomised to carry out avoidance procedures or to act as a control. The trial lasted eight weeks and histamine challenge was repeated at four and eight weeks.

Ten millilitre samples of venous blood were taken during the pretrial period and at eight weeks. Serum IgE antibodies to $D$ pteronyssinus were measured by the radioallergoabsorbent test (RAST), and total IgE antibodies by PRIST (Pharmacia UK Ltd).

\section{HOUSE DUST MITE AVOIDANCE MEASURES}

One of us (MJC) carried out fortnightly dust sampling, counting and identification of the mites and supervision of the avoidance measures. After the first samples had been taken the mattresses and bedroom carpets of patients in the avoidance group were soaked with liquid nitrogen as described elsewhere. ${ }^{9}$ Only numbers of $D$ pteronyssinus were recorded. They were graded as "damaged" or "intact" as an indication of whether they were alive or dead when sampled, ${ }^{10}$ and results were expressed as the number of mites extracted per $0.25 \mathrm{~m}^{2}$ of mattress per minute.
Further avoidance measures were performed by a third person such as a spouse or a parent. The entire surface of the bed was vacuumed weekly with special attention to seams, buttons, and box springs. Blankets, pillows, and duvets were cleaned at the beginning of the trial and sheets and pillow cases washed weekly. Blankets and upper sheets or duvets were folded back each morning to allow the mattress to air. Hard surfaces were damp dusted weekly. Plants, soft toys, cushions, and upholstered furniture were removed from the room. Patients in the control group were asked to continue with their normal cleaning activities.

\section{ANALYSIS}

Symptom scores were analysed by using the appropriate Wilcoxon's rank sum test (signed rank test for paired data, two sample test for unpaired data). Other data were assessed by two way analysis of variance (ANOVA). After ANOVA $t$ tests were used to locate the significant findings. Data on house dust mite numbers were transformed by $\log n+1$ transformation to make variance independent of mean. ANOVA was then carried out on transformed data.

\section{Results}

Three patients withdrew from the study after randomisation. In the control group one became too wheezy after contact with a newly acquired cat. In the avoidance group one left the area and another refused to cooperate. Nine patients in each group completed the study. One "avoidance" patient lost his diary cards so recordings were available only for eight patients within this group. There were no significant differences between the two groups in baseline severity of symptoms, the mean size of weals produced by house dust mite, the number of subjects sensitive to pollen on skin testing, $\mathrm{FEV}_{1}$ as a percentage of the predicted value, or geometric mean $\mathrm{PC}_{20} \mathrm{FEV}_{1}$ histamine (table 1). One

\section{Table 1 Patients' characteristics during the pretrial period}

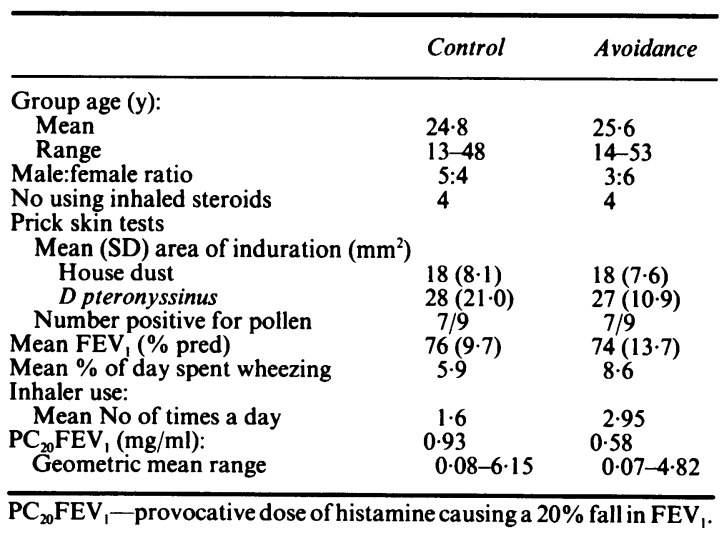




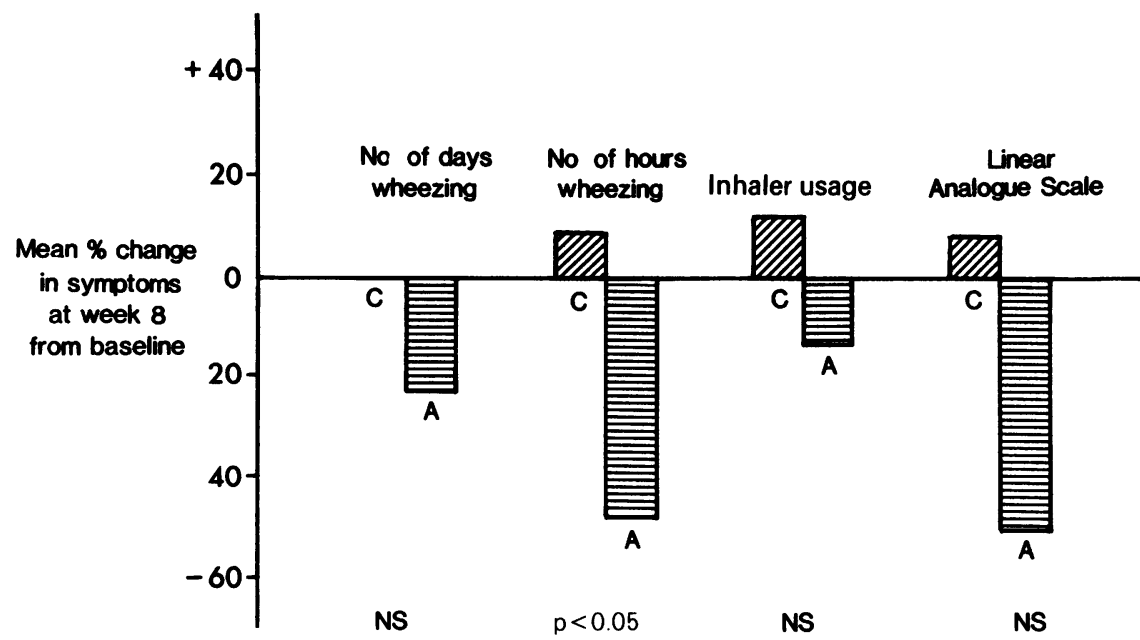

Fig 1 Mean percentage change in symptom scores from the pretrial period to the end of the study in control (C) and avoidance $\vec{c}$ (A) groups.

patient in the control group and two in the avoidance group reported having a "cold" during the eight week period, but no patient required oral steroids or any alteration of normal treatment.

In the control group there was a slight increase in the mean daily number of hours of wheezing, inhaler use, and symptoms as judged by the linear analogue scale, though none was statistically significant (fig 1). In the avoidance group there was a significant fall in the number of hours wheezing (from a mean of 8.6 to 4.5 ; $\mathrm{p}<0.01$ ) and in the linear analogue scale values (from $10 \mathrm{~mm}$ to $5 \mathrm{~mm}$ on a $100 \mathrm{~mm}$ scale; $\mathrm{p}<0.05$ ), though only the former reached significance when the two groups were compared $(\mathrm{p}<0.05)$ (fig 1). Mean morning PEF rose from 364 to $3881 / \mathrm{min}$ in the avoidance group ( $<<0.02)$, but did not alter significantly in the control group (from 402 to $392 \mathrm{l} / \mathrm{min}$ at 8 weeks). Similarly, the evening PEF rose from 368 to $3921 / \mathrm{min}$ in the avoidance group $(\mathrm{p}<0.05)$, but did not alter in the control group (from 388 to $3951 / \mathrm{min}$ at 8 weeks) (table 2). Geometric mean $\mathrm{PC}_{20}$ histamine values increased in the avoidance group from $0.58 \mathrm{mg} /$ $\mathrm{dl}$ during the run in period to $1.2 \mathrm{mg} / \mathrm{ml}$ at four weeks (not significant) and to $2.3 \mathrm{mg} / \mathrm{ml}$ at 8 weeks ( $\mathrm{p}<$ 0.01 ). In the control group there was no significant difference between baseline $(0.93 \mathrm{mg} / \mathrm{ml})$, four week $(1.26 \mathrm{mg} / \mathrm{ml})$, and eight week $(1.2 \mathrm{mg} / \mathrm{ml})$ mean values (fig 2). The change in $\mathrm{PC}_{20}$ histamine values in the avoidance group was significantly different from the change in the control group ( $p<0.02)$. In the control group only one patient had a change of more than two doubling doses (a threefold change) in $\mathrm{PC}_{20} \mathrm{FEV}_{1}$. In the avoidance group four patients had an increase of more than two doubling doses (a threefold increase) in $\mathrm{PC}_{20} \mathrm{FEV}$, histamine and none had a fall.

No change in either local IgE or allergen specific IgE antibody was detected in the patients in either group or between groups during the trial.

There was no significant change in the number of intact or damaged mites extracted from the mattresses or carpets of the control group during the study (table 2 ). The avoidance group had mean mite counts similar to those of the control group at the start of the study.

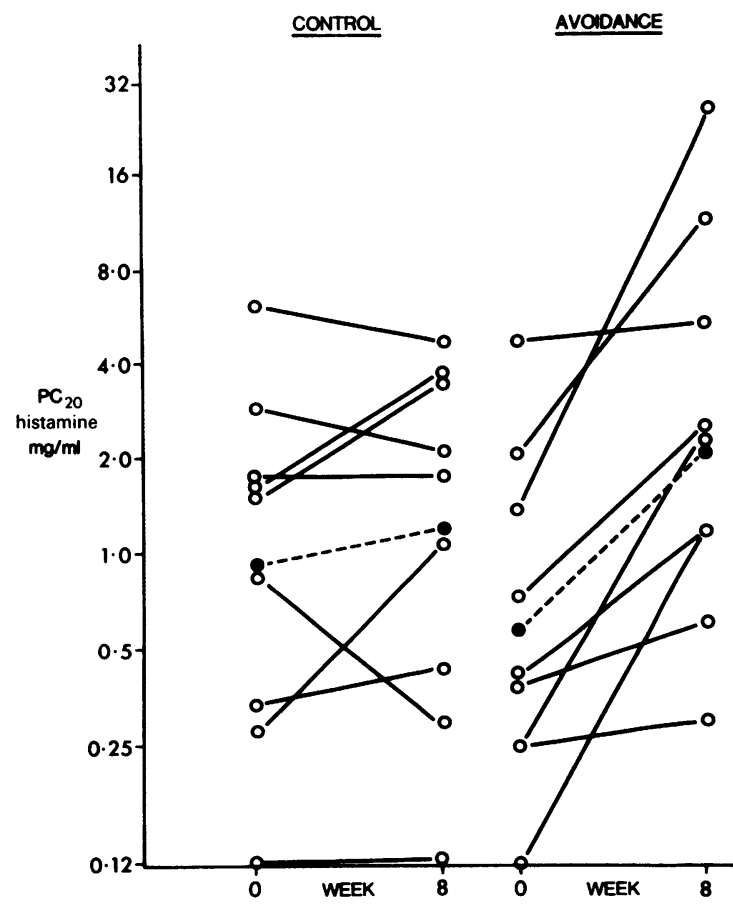

Fig 2 Individual values of $P C_{20}$ histamine $(\mathrm{mg} / \mathrm{ml})$ before the trial and at 8 weeks for the control and avoidance groups. Solid circles and hatched lines indicate geometric mean values of the group. 
Table $2 F E V_{1}$, peak expiratory flow and $P C_{20} F E V_{1}$ and numbers of intact mites extracted from mattresses before the trial and at 4 and 8 weeks in control and avoidance groups

\begin{tabular}{|c|c|c|c|c|c|c|}
\hline & \multicolumn{3}{|l|}{ Control } & \multicolumn{3}{|l|}{ Avoidance } \\
\hline & Pretrial & $4 w$ & $8 w$ & Pretrial & $4 w$ & $8 w$ \\
\hline $\begin{array}{l}\text { Mean (SD) FEV }(1) \\
\text { Mean (SD) peak flow (l/min) }\end{array}$ & $2.78(0.59)$ & $2.67(0.54)$ & $2.61(0.51)$ & $2.84(0.84)$ & $2.78(0.83)$ & $2 \cdot 74(0.81)$ \\
\hline $\begin{array}{l}\text { Morning } \\
\text { Evening } \\
\text { Geometric mean } \mathrm{PC}_{20} \mathrm{FEV}_{1}(\mathrm{mg} / \mathrm{ml}) \\
\text { Mean (SD) No of intact mites } \\
\text { extracted from mattresses } \\
\text { (per } 0.25 \mathrm{~m}^{2} / \mathrm{min} \text { ) }\end{array}$ & $\begin{array}{c}402(69) \\
388(55) \\
0.93\end{array}$ & $\begin{array}{c}390(75) \\
390(61) \\
1.26\end{array}$ & $\begin{array}{c}392(71) \\
395(65) \\
1.21\end{array}$ & $\begin{array}{c}364(101) \\
368(86) \\
0.58\end{array}$ & $\begin{array}{c}369(98) \\
375(92) \\
1.2\end{array}$ & $\begin{array}{l}388(106)^{*} \\
392(103)^{*} \\
2 \cdot 3^{* *}\end{array}$ \\
\hline
\end{tabular}

${ }^{*} \mathrm{p}<0.01,{ }^{* *} \mathrm{p}<0.01$ level of significance within each group.

$\mathrm{PC}_{20} \mathrm{FEV}$, - provocative dose of histamine causing $20 \%$ fall in $\mathrm{FEV}_{1}$.

The number of intact mites per $0.25 \mathrm{~m}^{2} / \mathrm{min}$ from the mattresses of patients in the avoidance group fell from a mean (SD) of 6.6 to $(6 \cdot 1)$ in the pretreatment sample to $0.3(1.3)$ by the end of the study $(p<0.01)$. The number of damaged mites extracted rose from $29(25)$ in the pretreatment sample to 39 (42) by week 2 , but were then reduced to $4.0(3.6)$ by week $8(p<0.01)$. The mean number of intact mites in the carpets of the avoidance group was also reduced (from 10.6(18.5) to $0.4(1.0) ; \mathrm{p}<0.05)$ by week 8 . There was, however, only a slight reduction in the number of damaged mites from carpets, from 31 (56) to 28 (66) (table 2).

\section{Discussion}

In this study modifying the bedroom environment of a group of adult patients with mild asthma with house dust mite allergy led to improved control of asthma symptoms and non-specific airway responsiveness that was significant when they were compared with a parallel control group. Increased non-specific airway responsiveness is one of the hallmarks of asthma. ${ }^{8}$ Allergen challenge produces acute bronchoconstriction in susceptible patients that may be followed by a late asthmatic response several hours after challenge. It may also produce an increase in non-specific airway responsiveness for days and sometimes weeks. ${ }^{11}$ 'This is more likely to occur in patients who develop a late asthmatic response," a response in which inflammation is thought to play a part. ${ }^{13}$ A near continuous exposure to small amounts of house dust mite allergen might produce a chronic inflammatory response, similar to the late response, resulting in a long term increase in bronchial reactivity. Thus the amount of house dust mite allergen may have to be reduced for some time before any improvement in airway reactivity occurs. Walshaw and Evans failed to show any improvement in histamine airway responsiveness until avoidance measures had continued for eight months. ${ }^{7}$ Platts-Mills et at found that it took more than a month before subjects with severe asthma put into a mite free environment started to show a decrease in bronchial reactivity. In our study patients in the avoidance group showed a tendency towards improvement by week 4 , which reached statistical significance by week 8 . Our patients may have improved at a faster rate because of the relative mildness of their asthma, and because of the initial success of liquid nitrogen in destroying the house dust mite.

Airway responsiveness may also alter with alterations in the calibre of the airway, but there was no evidence of a significant increase in $\mathrm{FEV}_{1}$ before challenge in either group to explain the improvement in histamine reactivity in our avoidance group. The improvement in airway responsiveness was mainly due to four individuals, who showed a decrease in airway reactivity well outside the natural variation of the tests. These patients were in the younger half of the age range. At the start of the study the avoidance group had symptoms similar to those of the control group but were slightly more responsive to histamine, though the difference was not significant. The improvement in airway reactivity was not, however, related to the initial severity of symptoms, skin sensitivity to house dust mite, or initial level of airway responsiveness. Thus the improvement in the avoidance group was not related to a greater initial severity. Apart from age it is difficult to predict from this small series which patient will benefit from avoidance measures. The improvement in bronchial reactivity was more striking than the changes in symptom scores. This may be explained in part by the difficulty in interpreting asthma diary cards, ${ }^{14}$ and may be the reason why studies that have not used an objective measurement such as bronchial reactivity have shown poor results in the past.

Some previous trials did not monitor house dust mite numbers during the avoidance procedure ${ }^{235}$ and some failed to show any significant reduction by comparison with a control group. ${ }^{615}$ Walshaw and 
Evans $^{7}$ showed a reduction in mite levels by using fairly vigorous cleaning procedures over a long period. The avoidance measures we advised were not as meticulous as those used in most previous studies-for example, mattresses were not enclosed in polythene sheets and carpets were not removed from bedrooms. The use of liquid nitrogen in our study resulted in the death of a large number of mites at the beginning of the study and these had been largely extracted from the mattresses by week 2 . The total number of mites was significantly reduced by week 8 and only $1 \%$ of mites were alive. Antigen P-1 is the major allergen of $D$ pteronyssinus and is concentrated in the faecal pellets. ${ }^{16}$ We suggest that a vigorous initial killing of house dust mites to halt the production of antigen P-1 is essential for a successful avoidance protocol. Vacuum cleaning can then be used to remove the residual allergen pool of faecal pellets and dead mites. Support for this idea comes from a recent study ${ }^{17}$ showing that a single application of the chemical acaracide without avoidance measures kills mites, and reduces the accumulation of antigen P-1 by $90 \%$ over six weeks.

No damage to mattresses or carpets was reported by any patient and no structural damage of mattress materials was seen by scanning electron microscopy after repeated immersion in liquid nitrogen. ${ }^{9}$ It is at present impracticable to use liquid nitrogen other than experimentally. Chemical acaracides of low intrinsic allergenicity may well prove to be a more practical solution to management of house dust mites in future.

\section{References}

1 Voorhorst R, Spieksma FThM, Varekamp H, Leupen MJ, Lyklema AW. The house dust mite (Dermatophagoides pteronyssinus) and the allergens it produces. Identity with the house-dust allergen. J Allergy 1967; 30:325-39.

2 Sarsfield JK, Gowland G, Toy R, Norman ALE. Mitesensitive asthma of childhood; trial of avoidance measures. Arch Dis Child 1974;49;716-21.

3 Murray AB, Ferguson AC. Dust-Free Bedrooms in the Treatment of Asthmatic Children with House Dust or House Dust Mite Allergy: a Controlled Trial. Pediatrics 1983;71:418-22.

4 Platts-Mills TAE, Tovey ER, Mitchell EB, Moszoro H,
Nock P, Wilkins SR. Reduction of bronchial hyperreactivity during prolonged allergen avoidance. Lancet 1982; ii:675-8.

5 Burr ML, St Leger AS, Neale E. Anti-mite measures in mite-sensitive adult asthma. A controlled trial. Lance 1976;i:333-5.

6 Korsgaard J. Preventitive measures in mite asthma. A controlled trial. Allergy 1983;38:93-102.

7 Walshaw MJ, Evans CC. Allergen avoidance in house dust mite sensitive adult asthma. $Q J$ Med 1986;58 199-215.

8 Hargreave FE, Ryan G, Thomson NC, O'Byrne PM, Latimer K, Juniper E, Dolovitch J. Bronchial responsiveness to histamine or methacholine in asthma: Measurement and clinical significance. J Allergy Clin Immunol 1981;68:347-55.

9 Colloff MJ. The use of liquid nitrogen in the control of house dust mite population. Clin Allergy 1986;16: $41-47$.

10 Arlian LG, Bernstein IL, Gallagher JS. The prevalence of house dust mites, Dermatophagoides spp., and associated environmental conditions in homes in Ohio. J Allergy Clin Immunol 1982;69:527-32.

11 Cockcroft DW, Ruffin RE, Dolovitch J, Hargreave FE. Allergen-induced increase in non-allergic bronchial reactivity. Clin Allergy 1977:7:503-13.

12 Boulet LP, Cartier A, Thomson NC, Roberts RS, Dolovitch J, Hargreave FE. Asthma and increases in non-allergic bronchial responsiveness from seasonal pollen exposure. J Allergy Clin Immunol 1983;71: 399-406.

13 Kaliner MA. Hypothesis on the contribution of latephase allergic responses to the understanding and treatment of allergic diseases. J Allergy Clin Immunol 1984;73:311-5.

14 Nunn AJ. Are we sure it works? In: Green M, ed. Asthma drugs - trials and tribulations. Oxford: Medicine Publishing Foundation, 1984;33-42.

15 Burr ML, Dean BV, Merrett TG, Neale E, St Leger AS, Verrier-Jones ER. Effects of anti-mite measures on children with mite-sensitive asthma: a controlled trial. Thorax 1980;35:506-12.

16 Tovey ER, Chapman MD, Platts-Mills TAE. Mite faeces are a major source of house dust mite allergens. Nature 1981;289:592-3.

17 Mitchell EB, Wilkens S, Deighton JM, Platts-Mills TAE. Reduction of the house dust mite allergen levels in the home; use of the acaracide purimiphos methyl. Clin Allergy 1985;15:235-40. 